\section{Commentary: Moving beyond phenotypic diagnosis}

\author{
William E. Stansfield, MD, CM, FACS
}

French pediatrician Antoine Marfan first described the syndrome that bears his name in 1896, observing the physical traits of a young patient. Over time, it became clear that these characteristics could run in families or could appear de novo. Marfan remained a clinically diagnosed syndrome - a constellation of traits-until 1991, when it was conclusively associated with defects in FBN1, ${ }^{1}$ the gene encoding extracellular matrix protein fibrillin-1. Five years later, the Gent nosology for clinical classification ${ }^{2}$ added consideration for molecular testing. The 2010 revised Gent criteria ${ }^{3}$ give greater weight to genetic testing but remain primarily based on phenotypic trait assessment.

In 2010, state-of-the-art genetic testing meant examining a patient's DNA for the presence or absence of specific mutations known to cause disease. This was a reasonable strategy when searching for the most common mutations, but many patients with less-common mutations were undoubtedly missed. Now, for a few hundred dollars, we can obtain the complete sequence of every protein-coding gene in the patient's entire genome. Known as whole-exome sequencing, this technology enables detailed analysis of both the gene of interest (FBN1) as well as related genes (eg, FBN2, TGFBR1/2). With information this specific, we may eventually understand the molecular basis for the pleiotropic effects of diseases like Marfan syndrome.

In their case report, Brahmandam and Vallabhajosyula ${ }^{4}$ used whole-exome sequencing to identify a novel and rare fibrillin mutation in 2 adult patients. Mother and son

From Cardiothoracic and Vascular Surgery, Advocate Christ Medical Center, Oak Lawn, Ill.

Disclosures: The author reported no conflicts of interest.

The Journal policy requires editors and reviewers to disclose conflicts of interest and to decline handling or reviewing manuscripts for which they may have a conflict of interest. The editors and reviewers of this article have no conflicts of interest.

Received for publication Dec 16, 2020; revisions received Dec 16, 2020; accepted for publication Dec 23, 2020; available ahead of print Dec 27, 2020.

Address for reprints: William E. Stansfield, MD, CM, FACS, Cardiothoracic and Vascular Surgery, Advocate Christ Medical Center, Oak Lawn, IL 60453

(E-mail: wstansfi@gmail.com).

JTCVS Techniques 2021;6:44-5

2666-2507

Copyright $@ 2020$ The Authors. Published by Elsevier Inc. on behalf of The American Association for Thoracic Surgery. This is an open access article under the CC BY-NCND license (http://creativecommons.org/licenses/by-nc-nd/4.0/).

https://doi.org/10.1016/j.xjtc.2020.12.025

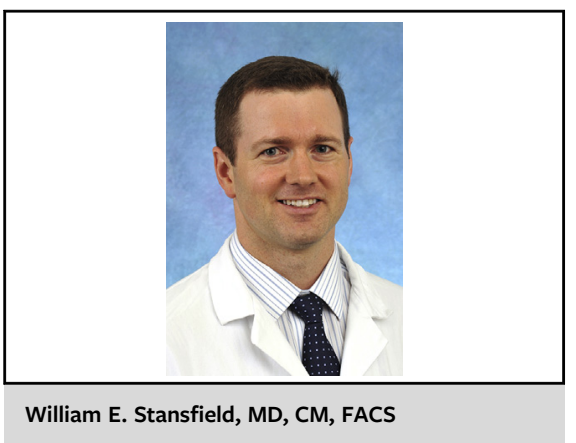

CENTRAL MESSAGE
Whole-exome screening is a
powerful and cost-effective tool
allowing clinicians to readily
identify rare genetic mutations
with meaningful implications for
patients and their families.

displayed distinct aortic pathologies but serendipitously presented at the same time to the same treatment team. Neither patient had clinical features of a connective tissue disorder. Neither patient had Marfan syndrome according to the revised Ghent criteria. Only a few years ago, testing strategies would likely have missed this rare variant in FBN1 and the familial connection it indicates. Fortunately, both patients received the medical and surgical therapies needed to restore their health. Family screening may result in even greater benefits.

Our tools now far exceed the visual observations that once characterized medical diagnosis. We can literally look inside a patient's DNA and examine the variations that both make that patient unique and that put them at risk. We can do this for approximately the same price as a computed tomography scan. The need for complex aggregate phenotypic labeling has passed. What we need now is a 21 st-century system for risk stratification and identification of patients - and their families-who benefit from screening for treatable conditions. We have amazing diagnostic and therapeutic implements at our disposal. Let's use them!

\section{References}

1. Lee B, Godfrey M, Vitale E, Hori H, Mattei MG, Sarfarazi M, et al. Linkage of Marfan syndrome and a phenotypically related disorder to two different fibrillin genes. Nature. 1991;352:330-4.

2. De Paepe A, Devereux RB, Dietz HC, Hennekam RC, Pyeritz RE. Revised diagnostic criteria for the Marfan syndrome. Am J Med Genet. 1996;62:417-26. 
3. Loeys BL, Dietz HC, Braverman AC, Callewaert BL, De Backer J, Devereux RB, et al. The revised Ghent nosology for the Marfan syndrome. J Med Genet. 2010; $47: 476-85$.
4. Brahmandam A, Vallabhajosyula P. Novel fibrillin-1 mutation with variable presentation as a thoracic aortic aneurysm and intramural hematoma. J Thorac Cardiovasc Surg Tech. 2021;6:39-41. 